\title{
Blood pressure and falls in community-dwelling people aged 60 years and older in the VHM\&PP cohort
}

\author{
Diana Klein ${ }^{1 *}$, Gabriele Nagel ${ }^{2,3}$, Andrea Kleiner $^{2}$, Hanno Ulmer ${ }^{4}$, Barbara Rehberger ${ }^{3}$, Hans Concin ${ }^{3}$ \\ and Kilian Rapp ${ }^{1,2}$
}

\begin{abstract}
Background: Falls are one of the major health problems in old people. Different risk factors were identified but only few epidemiological studies analysed the influence of conventionally measured blood pressure on falls. The objective of our study was to investigate the relationship between systolic and diastolic blood pressure and falls.

Methods: In 3,544 community-dwelling Austrian women and men aged 60 years and older, data on falls within the previous three months were collected by questionnaire. Blood pressure was measured by general practitioners within the Vorarlberg Health Monitoring and Prevention Programme (VHM\&PP) 90 to 1095 days before the fall assessment. A multiple logistic regression analysis was conducted. The models were stratified by gender and adjusted by age, number of medical conditions and subjective feeling of illness.

Results: In total, 257 falls in 3,544 persons were reported. In women, high systolic and diastolic blood pressure was associated with a decreased risk of falls. An increase of systolic blood pressure by $10 \mathrm{mmHg}$ and of diastolic blood pressure by $5 \mathrm{mmHg}$ reduced the risk of falling by $9 \%(\mathrm{OR} 0.91,95 \% \mathrm{Cl} 0.84-0.98)$ and $8 \%(\mathrm{OR} 0.92,95 \% \mathrm{Cl}$ 0.85-0.99), respectively. In men, an increased risk of falls was observed in participants with low systolic or low diastolic blood pressure.
\end{abstract}

Conclusions: Blood pressure was associated with the risk of falls. Hypertensive values decreased the risk in women and low blood pressure increased the risk in men.

Keywords: Falls, Blood pressure, Hypotension, Risk factors

\section{Background}

Falls are one of the major health problems in old people. About one third of people aged 65 years and older report at least one fall per year [1]. Consequences can be injuries such as fractures of the hip, the humerus or the forearm, fear of falling, loss of independence and increased mortality [2-4]. Different risk factors for falls including functional limitations and several diseases have been identified [5]. Cardiovascular diseases, for example, have been found to be associated with falls, mostly as a result of hypotensive episodes [6,7]. Blood pressure (BP) is one of the leading risk factors for cardiovascular

\footnotetext{
* Correspondence: diana.klein@rbk.de

'Department of Clinical Gerontology, Robert-Bosch-Hospital, Stuttgart, Germany

Full list of author information is available at the end of the article
}

diseases. Increasing BP has been shown to be linearly associated with cardiovascular disease and mortality. Therefore, low BP values have been usually regarded as a protective factor for different diseases and death $[8,9]$.

In old people, however, there is evidence that the positive relationship between BP and mortality is weakened and that a low BP may even increase mortality [10-12]. For example, in the INVEST-study a J-curve between BP and adverse outcomes (all-cause mortality, nonfatal myocardial infarction or nonfatal stroke) was observed with an increased risk in participants with a very low and a very high BP [13].

Orthostatic hypotension has been shown to be a risk factor for recurrent falls in nursing home residents [14] and in people living in apartments for the elderly [15]. However, assessing orthostatic hypotension is relatively

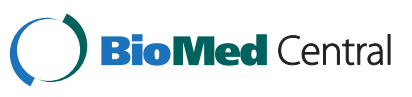


time-consuming and Schellong tests or tilt table testing are rarely performed in daily practice. In contrast, simple $\mathrm{BP}$ measurements are one of the basic examinations and available for nearly every patient. It is therefore surprising that only few epidemiological studies exist which analysed the influence of conventionally measured BP on falls.

The objective of our study was to investigate the relationship between BP and falls in more than 3,500 community-dwelling people aged 60 years and older.

\section{Methods}

\section{Study design and study population}

Data from the Austrian Vorarlberg Health Monitoring and Prevention Programme (VHM\&PP) were analysed. In Vorarlberg, the westernmost province of Austria, medical examinations are routinely performed by general practitioners within the VHM\&PP. All Austrian citizens aged 19 years and older can voluntarily participate in these examinations once a year. The participation must be arranged on ones own initiative and costs are covered by the participant's health insurance. The medical examinations include amongst others, the measurement of BP. The VHM\&PP has been described in detail previously [16].

Between 2000 and 2004 patients aged 60 years and older were asked to complete an additional questionnaire on age-related health which included questions about their current health status, living conditions, their functional impairments or falls. The questionnaire was handed out before or directly at the health examination and completed at home. All participants gave their written informed consent. For this study, institutional review board approval was obtained by the Ethics Committee of the province of Vorarlberg.

The current analysis was restricted to participants $(\mathrm{N}=3,544)$ who had a health examination 90 to 1095 days prior to completing the questionnaire. If participants attended more than one health examination during this period, the $\mathrm{BP}$ measurements of the latest examination was matched to the information of the questionnaire. A minimum of 90 days was chosen in order to enable a prospective analysis since falls were assessed retrospectively over a period of three months (see below). BP is a dynamic value which may change over time. Therefore, a maximum of 1095 days (i.e. three years) was chosen to increase the propensity that the exposition was actually associated with the outcome.

\section{Outcome}

The outcome variable of the study was a fall. Fallers were defined as those who reported one or more falls during the last three months. This was assessed by the questionnaire: "Did you fall in the previous three months?"

\section{Blood pressure}

Systolic (SBP) and diastolic (DBP) blood pressure were measured at the medical examination in sitting position with a mercury sphygmomanometer. SBP and DBP were analysed as continuous, dichotomous and categorical variables. The dichotomous variable differentiated BP values regarded as normotensive or hypertensive $(<140$ and $\geq 140 \mathrm{mmHg}$ for SBP and $<90$ and $\geq 90 \mathrm{mmHg}$ for DBP) [8]. For the categorical variable SBP was divided in intervals of $20 \mathrm{mmHg}(<120,120-<140,140-<160$, $160-<180, \geq 180)$ and DBP in intervals of $10 \mathrm{mmHg}(<80$, $80-<90,90-<100, \geq 100)$. The normotensive intervals $(120-<140 \mathrm{mmHg}$ for SBP and $80-<90 \mathrm{mmHg}$ for DBP) were used as reference categories. In men, the two highest categories were combined to guarantee at least 10 falls in each category. The mean arterial pressure (MAP) was calculated as DBP $+1 / 3$ (SBP-DBP) and included in the model only as a continuous variable.

\section{Covariates}

In order to adjust the model for co-morbidity, number of medical conditions and subjective feeling of illness were included. Medical conditions were assessed in the questionnaire by the following questions: 'Are you or have you been under medical treatment because of (1) high blood pressure (hypertension), (2) other cardiovascular diseases or stroke, (3) pulmonary diseases, (4) diabetes mellitus, (5) cancer, (6) chronic urinary tract infection or (7) other diseases'. Through addition of the positive answers of the single items an additive co-morbidity score was built (range 0-7) and included in the model as continuous variable. Subjective feeling of illness was measured by asking 'Do you currently feel sick?' (yes/no). Self-rated health has been shown to be a good independent predictor of morbidity and all-cause mortality $[17,18]$. Therefore, subjective feeling of illness was included as a second covariate for the participant's health status in the fully adjusted model.

Information about the use of BP medication was only based on the question if the participants are or have been under medical treatment for hypertension and was collected at the end of the study. The questionnaire did not provide information if the participants actually used $\mathrm{BP}$ medication at the time of the BP measurement. Therefore, information about the use of antihypertensives at baseline may be inaccurate.

\section{Statistical analysis}

A multiple logistic regression analysis was conducted to calculate odds ratio (OR) of falls. BP was included into the models as continuous, dichotomous and categorical variable. Presented are associations adjusted for age (model 1) and for age, subjective feeling of illness and 
number of medical conditions (model 2). All analyses were stratified by gender.

Furthermore, in three different supplementary analyses model 2 was either adjusted for antihypertensive treatment, or stratified by age (the median of age served as cut-point) or by time period between BP measurement and outcome (the median of days served as cut-point). Effect modification between SBP or DBP and antihypertensive treatment was analysed by including an interaction term in the model.

\section{Results}

The study consisted of 1,970 women and 1,574 men with a median age of 70 and 69 years, respectively. About $9 \%$ of the women and $5 \%$ of the men reported at least one fall within the three months before completing the questionnaire. A hypertensive SBP $(\geq 140 \mathrm{mmHg}$ ) was measured in $70.5 \%$ of the female and $67.6 \%$ of the male study population. The proportion of women and men with a DBP defining hypertension ( $\geq 90 \mathrm{mmHg}$ ) was considerably lower. A subjective feeling of illness was reported by $17.2 \%$ of the women and $13.6 \%$ of the men (Table 1).

In women, increasing blood pressure values were associated with a decreased risk of falls, with hypertensives showing a decreased risk compared with normotensives, and the protective effect being stronger for DBP. In the fully adjusted model an increase of SBP by $10 \mathrm{mmHg}$ and of DBP by $5 \mathrm{mmHg}$ reduced the risk of a fall by 9\% (Odds ratio (OR) 0.91, 95\% confidence interval $(\mathrm{Cl})$
0.84-0.98) and 8\% (OR 0.92, 95\% Cl 0.85-0.99), respectively. Women with a DBP of at least $100 \mathrm{mmHg}$, for example, had only half the fall risk compared to women with a DBP between 80 and $90 \mathrm{mmHg}$. For increasing categorical $\mathrm{BP}$ values decreasing risk estimates were observed. In contrast to DBP estimates for SBP did not reach statistical significance (Table 2).

Men showed a clearly increased risk for low SBP $(<120 \mathrm{mmHg})$ and DBP $(<80 \mathrm{mmHg})$ with a 2.5 times and 1.8 times higher risk of falling than those with 'high normal' values, respectively. No significant association between BP as a continuous or a dichotomous variable and falls was found (Table 2).

In the analysis stratified by age, the association between SBP and falls were only observed in women and men over 70 years. In contrast, an association between DBP and falls was found in women in the younger age-group and in men in the older age-group (Additional file 1: Table SA).

An additional analysis was performed stratified by the time period between BP measurement and outcome. In men, a stronger association was observed when the time period between BP measurement and outcome was closer. In women, the time period had no considerable effect on the estimates (Additional file 2: Table SB).

The additional adjustment of the model by 'antihypertensive treatment' did not change the estimates considerably and no significant effect modification between SBP or DBP and antihypertensive treatment was observed (Additional file 3: Table SC).

Table 1 Characteristics of the study population

\begin{tabular}{|c|c|c|c|c|}
\hline & \multicolumn{2}{|c|}{ Women } & \multicolumn{2}{|c|}{ Men } \\
\hline & $\mathrm{N}$ & Falls N (\%) & $\mathrm{N}$ & Falls N (\%) \\
\hline Participants (N) & 1970 & $180(9.1 \%)$ & 1574 & $77(4.9 \%)$ \\
\hline \multicolumn{5}{|l|}{ Systolic blood pressure $(\mathrm{mmHg})$} \\
\hline$<120$ & 87 & $10(11.5 \%)$ & 95 & $10(10.5 \%)$ \\
\hline $120-139$ & 495 & $51(10.3 \%)$ & 415 & $19(4.6 \%)$ \\
\hline $140-159$ & 825 & $73(8.8 \%)$ & 651 & $28(4.3 \%)$ \\
\hline $160-179$ & 389 & $33(8.5 \%)$ & 293 & $14(4.8 \%)$ \\
\hline$\geq 180$ & 174 & $13(7.5 \%)$ & 120 & $6(5.0 \%)$ \\
\hline \multicolumn{5}{|l|}{ Diastolic blood pressure $(\mathrm{mmHg})$} \\
\hline$<80$ & 386 & $38(9.8 \%)$ & 316 & $23(7.3 \%)$ \\
\hline $80-89$ & 955 & $100(10.5 \%)$ & 816 & $34(4.2 \%)$ \\
\hline $90-99$ & 434 & $31(7.1 \%)$ & 330 & $15(4.5 \%)$ \\
\hline$\geq 100$ & 195 & $11(5.6 \%)$ & 112 & $5(4.5 \%)$ \\
\hline Age, median (range), (years) & \multicolumn{2}{|c|}{$70(60-97)$} & \multicolumn{2}{|c|}{$69(60-91)$} \\
\hline Number of medical conditions*, median (range) & \multicolumn{2}{|c|}{$1(0-7)$} & \multicolumn{2}{|c|}{$1(0-6)$} \\
\hline Subjective feeling of illness ${ }^{\dagger}, \mathrm{N}(\%)$ & \multicolumn{2}{|c|}{338 (17.2\%) } & \multicolumn{2}{|c|}{$214(13.6 \%)$} \\
\hline
\end{tabular}

* Assessed medical conditions: high blood pressure (hypertension); other cardiovascular diseases or stroke; pulmonary diseases; diabetes mellitus; cancer; chronic urinary tract infection; other diseases.

' Assessed by the question 'Do you currently feel sick?' (yes/no). 
Table 2 Influence of systolic, diastolic and mean arterial blood pressure on falls in women and men aged 60 years and older in the VHM\&PP cohort

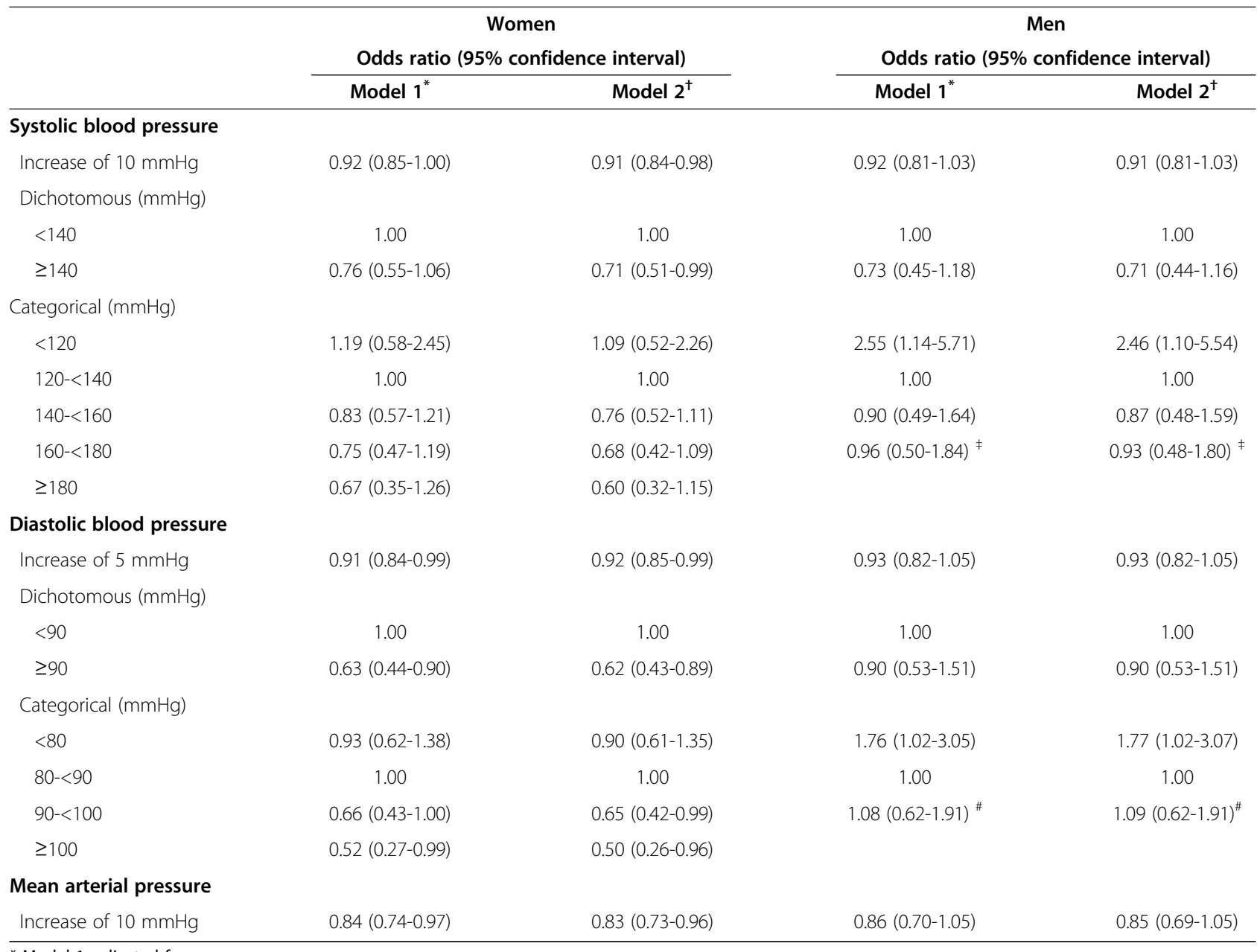

* Model 1: adjusted for age.

† Model 2: adjusted for age, subjective feeling of illness and number of medical conditions.

₹ Systolic blood pressure $\geq 160 \mathrm{mmHg}$.

\# Diastolic blood pressure $\geq 90 \mathrm{mmHg}$.

\section{Discussion}

We observed a decreased risk of falls in women with hypertensive values for SBP and DBP and an increased risk of falls in men with low SBP or DBP. In men, the association between $\mathrm{BP}<120 / 80 \mathrm{mmHg}$ and falls was limited to participants over 70 years. Therefore, a BP which is regarded as optimal in a cardiovascular point of view may actually be risky concerning falls in the oldest men. The cause of the gender difference remained unclear and requires replication in further studies.

There are only few epidemiological studies which analysed the association between conventionally measured BP and falls. Kario [19] identified lower SBP as an independent predictor of falls in relatively healthy community-dwelling older people. The association was stronger in women than in men. In this study, however, BP was assessed in supine and standing position.
Participants with a standing SBP below $140 \mathrm{mmHg}$ had a 2.8 times increased risk of falls compared to people from the reference group $(\geq 140 \mathrm{mmHg})$. DBP was not related to falls. In our study low SBP was shown to be a significant predictor of falls only in men. In women, higher values of DBP were associated with a decreased risk of falling.

Two meta-analyses of observational studies found both a slight to moderate increased risk of falls with antihypertensive treatment $[20,21]$ and van der Velde and colleagues demonstrated a significant reduction of falls after withdrawal of cardiovascular medications [22]. On the other hand, the randomised controlled HYVET study demonstrated convincingly that the treatment of old and very old people with BP values of $160 / 90 \mathrm{mmHg}$ and more reduced their cardiovascular and total mortality. The target BP for patients aged 80 years and more was 
$150 / 80 \mathrm{mmHg}$ and it remained unclear if a further reduction of $\mathrm{BP}$ is beneficial [23]. Like in all other medication phase III trials falls were not assessed as an additional adverse outcome in old people. In our analysis there was no effect modification between BP and antihypertensive treatment and adjustment for antihypertensive treatment did not change the results considerably. This is consistent with the study from Kario [19]. However, our data quality regarding the use of antihypertensive drugs was low and the results should therefore be interpreted with caution.

Several studies analysed the effect of orthostatic hypotension on falls. Orthostatic hypotension is defined as a decline of SBP or DBP of at least 20 or $10 \mathrm{mmHg}$ within three minutes after transfer from sitting to standing, respectively. In some studies, orthostatic hypotension seemed to be a cause of (pre)syncopal episodes and falls in adults over 65 years of age [24-26]. Ooi et al., for example, identified orthostatic hypotension as an independent risk factor for recurrent falls in residents of nursing homes [14]. In contrast, another study in residents of nursing homes did not find orthostatic hypotension to be associated with falls [27]. In a study in community-dwelling people, orthostatic hypotension was most pronounced in patients with uncontrolled hypertension. In these patients the risk of falls was 2.5 times higher than in patients with uncontrolled hypertension but without an orthostatic hypotensive reaction. However, if all study participants independent of their baseline BP were included in the analysis, no association was found between orthostatic hypotension and falls [6].

The pathophysiological mechanism of an increased risk of falls in people with low BP or orthostatic hypotension may be partly due to changes in arterial structure and function such as vascular stiffness, calcification, collagen deposition and less distensibility of vessels. This may impair auto-regulation of BP and cause orthostatic hypotension and falls [28]. Our results suggest, whereby orthostatic dysregulation is not taken into account, that a lower baseline BP may imply an insufficient cerebral blood supply after a transfer to a standing position or whilst standing or walking which may be a hypothetical mechanism linking low BP with an increased fall risk. Recently higher systolic blood pressure has been shown to be associated with a lower annual increase in disability in the activities of daily living (ADL) and a lower annual decline in cognition [29]. Both variables are known to be associated with fall risk [5]. Disability in ADLs or cognition could be therefore mediating factors between $\mathrm{BP}$ and falls.

The strengths of the study are the longitudinal design and the large number of subjects. BP was measured in a standardized way by a health professional. The population of Vorarlberg is culturally and ethnically rather homogenous, with more than $90 \%$ of Austrian origin [16].

Our study has several limitations. Since there was no measurements in standing position it remains unclear if the observed effect was mediated by orthostatic dysregulation. Therefore, the pathophysiological mechanism remains hypothetical. Despite the large sample size, the number of participants and falls were low in some subgroups which reduced the statistical power of the analyses. Established risk factors for falls such as muscle weakness, imbalance, low walking speed [5] or the result of a cognition assessment, like the Mini Mental State Examination, were not available and therefore not adjusted for. However, the adjustment for co-morbidity (number of medical conditions) and subjective feeling of illness may have compensated to some extent the lack of further risk factors. In addition, we adjusted for the subjective reporting of 'forgetfulness' (data not shown), which did not change the estimates considerably. But even though we adjusted for co-morbidity residual confounding may have occurred. In addition, an underlying disease like heart failure, for example, may have been associated both with hypotension and falls. The study has a longitudinal nature since BP was measured before falls occurred. Falls, however, were assessed retrospectively by a questionnaire and could have therefore been subject for recall bias. Furthermore, the assessment of falls did not allow discriminating single fallers from frequent fallers.

The participants of the present study were probably in a relatively good health status since the preconditions to participate included the ability of a visit at the practice of the general practitioner in order to take part in the medical health examination and a fairly good cognitive state in order to complete the questionnaire. Furthermore, the initiative for participating in the examination was entirely left to the individuals. Thus, persons with mobility restrictions, care need, or impaired cognition like institutionalised people may have been underrepresented. This limits the external validity of our results, particularly since orthostatic BP dysregulation and falls are highly prevalent in very frail people $[14,30]$.

\section{Conclusions}

There is virtually no study which analysed the association between conventionally measured BP and falls. In the present study, high SBP and, more clearly, DBP were associated with a decreased risk of falls in women. In men low SBP or DBP were associated with an increased risk of falls. In daily practice BP is measured in most patients and patients with hypotension are easily recognisable. When treating them their fall risk should also be considered. 


\section{Additional files}

Additional file 1: Table SA. Influence of systolic, diastolic and mean arterial blood pressure on falls in women and men aged 60 years and older stratified by age in the VHM\&PP cohort.

Additional file 2: Table SB. Influence of systolic, diastolic and mean arterial blood pressure on falls in women and men aged 60 years and older stratified by the time period between BP measurement and outcome in the VHM\&PP cohort.

Additional file 3: Table SC. Influence of systolic, diastolic and mean arterial blood pressure on falls additionally adjusted for BP treatment in women and men aged 60 years and older in the VHM\&PP cohort.

\section{Competing interests}

The authors declare that they have no competing interests.

\section{Authors' contributions}

DK contributed by conception of the evaluation, analysis and interpretation of data and drafting the article. GN contributed by interpretation of data and drafting the article. AK contributed by analysis and interpretation of data. HU contributed by interpretation of data and drafting the article. BR contributed by conception of the study, interpretation of data and drafting the article. $\mathrm{HC}$ contributed by conception of the study, interpretation of data and drafting the article. KR contributed by conception of the evaluation, analysis and interpretation of data and drafting the article. All authors read and approved the final manuscript.

\section{Acknowledgements}

We are grateful to all the general practitioners taking part in the VHM\&PP. The VHM\&PP is supported by the State of Vorarlberg, Austria. We thank Markus Wallner, Christian Bernhard, Andrea Kaufmann, and Gabriela Dür from the Vorarlberg State Government.

\section{Author details}

${ }^{1}$ Department of Clinical Gerontology, Robert-Bosch-Hospital, Stuttgart, Germany. ${ }^{2}$ Institute of Epidemiology and Medical Biometry, Ulm University, Ulm, Germany. ${ }^{3}$ Agency for Social- and Preventive Medicine, Bregenz, Austria. ${ }^{4}$ Department of Medical Statistics, Informatics and Health Economics, Innsbruck Medical University, Innsbruck, Austria.

Received: 31 October 2012 Accepted: 10 May 2013

Published: 21 May 2013

\section{References}

1. Tinetti ME, Speechley M, Ginter SF: Risk factors for falls among elderly persons living in the community. N Engl J Med 1988, 319:1701-1707.

2. Campbell JA, Borrie MJ, Spears GF, Jackson SL, Brown JS, Fitzgerald JL: Circumstances and consequences of falls experienced by a communitypopulation 70 years and over during a prospective study. Age Ageing 1990, 19:136-142.

3. Kannus P, Parkkari J, Koskinen S, Niemi S, Palvanen M, Jaervinen M, Vuori I: Fall-induced injuries and deaths among older adults. JAMA 1999, 281:1895-1899.

4. Rubenstein LZ, Josephson KR: The epidemiology of falls and syncope. Clin Geriatr Med 2002, 18:141-158.

5. Deandrea S, Lucenteforte E, Bravi F, La Vecchia C, Negri E: Risk factors for falls in community-dwelling older people: a systematic review and meta-analysis. Epidemiology 2010, 21:658-668.

6. Gangavati A, Hajjar I, Quach L, Jones RN, Kiely DK, Gagnon P, Lipsitz LA: Hypertension, orthostatic hypotension, and the risk of falls in a community-dwelling elderly population: the maintenance of balance, independent living, intellect, and zest in the elderly of boston study. J Am Geriatr Soc 2011, 59:383-389.

7. Carey BJ, Potter JF: Cardiovascular causes of falls. Age Ageing 2001, 30(Suppl 4):19-24.

8. Chobanian AV, Bakris GL, Black HR, Cushman WC, Green LA, Izzo J, Jones DW, Materson BW, Oparil S, Wright JT, Roccella EJ, National High Blood Pressure Education Program Coordinating Committee: Seventh report of the joint national committee on prevention, detection, evaluation, and treatment of high blood pressure. Hypertension 2003, 42:1206-1252.

9. World Health Organization: World Health Organization (WHO)/ International Society of Hypertension (ISH) statement on management of hypertension. J Hypertens 2003, 21:1983-1992.

10. Bulpitt CJ, Fletcher AE: Aging, blood pressure and mortality. J Hypertens 1992, 10(Suppl 7):S45-S49.

11. Van Bemmel T, Gussekloo J, Westendorp RG, Blauw GJ: In a population-based prospective study, no association between high blood pressure and mortality after age 85 years. J Hypertens 2006, 24:287-292

12. Molander L, Loevheim H, Norman T, Nordstroem P, Gustafson Y: Lower Systolic blood pressure is associated with greater mortality in people aged 85 and older. J Am Geriatr Soc 2008, 56:1853-1859.

13. Denardo SJ, Gong Y, Nichols WW, Messerli FH, Bavry AA, Cooper-DeHoff RM, Handberg EM, Champion A, Pepine CJ: Blood pressure and outcomes in very old hypertensive coronary artery and disease patients: an INVEST substudy. Am J Med 2010, 123:719-726.

14. Ooi WL, Hossain M, Lipsitz LA: The association between orthostatic hypotension and recurrent falls in nursing home residents. Am J Med 2000, 108:106-111.

15. Graafmans WC, Ooms ME, Hofstee HM, Bezemer PD, Bouter LM, Lips P: Falls in the elderly: a prospective study of risk factors and risk profiles. Am J Epidemiol 1996, 143:1129-1136.

16. Ulmer $\mathrm{H}$, Kelleher $\mathrm{C}$, Diem G, Concin H: Long-term tracking of cardiovascular risk factors among men and women in a large population-based health system. Eur Heart J 2003, 24:1004-1013.

17. Idler EL, Benyamini Y: Self-rated health and mortality: a review of twenty-seven community studies. J Health Soc Behav 1997, 38:21-37.

18. Arnadottir SA, Gunnarsdottir ED, Stenlund H, Lundin-Olsson L: Determinants of self-rated health in old age: a population-based, cross-sectional study using the international classification of functioning. BMC Public Health 2011, 11:1-9.

19. Kario K, Tobin JN, Wolfson LI, Whipple R, Derby CA, Singh D, Marantz PR, Wassertheil-Smoller S: Lower standing systolic blood pressure as a predictor of falls in the elderly: a community-based prospective study. J Am Coll Cardiol 2001, 38:246-252.

20. Leipzig RM, Cumming RG, Tinetti ME: Drugs and falls in older people: a systematic review and meta-analysis: II. cardiac and analgesic drugs. J Am Geriatr Soc 1999, 47:40-50.

21. Woolcott JC, Richardson KJ, Wiens MO, Patel B, Marin J, Khan KM, Marra CA: Meta-analysis of the impact of 9 medication classes on falls in elderly persons. Arch Intern Med 2009, 169:1952-1960.

22. van der Velde N, Stricker BH, Pols HA, van der Cammen TJ: Risk of falls after withdrawal of fall-risk-increasing drugs: a prospective sohort study. Br J Clin Pharmacol 2006, 63:232-237.

23. Beckett NS, Peters R, Fletcher AE, Staessen JA, Liu L, Dumitrascu D, Stoyanovsky $V$, Antikainen RL, Nikitin Y, Anderson C, Belhani A, Forette F, Rajkumar C, Thijs L, Banya W, Bulpitt CJ: Treatment of hypertension in patients 80 years of age or older. N Engl J Med 2008, 358:1887-1898.

24. Rutan GH, Hermanson B, Bild DE, Kittner SJ, LaBaw F, Tell GS: Orthostatic hypotension in older adults. The cardiovascular health study. $\mathrm{CHS}$ collaborative research group. Hypertension 1992, 19:508-519.

25. Gupta V, Lipsitz LA: Orthostatic hypotension in the elderly: diagnosis and treatment. Am J Med 2007, 120:841-847.

26. Heitterachi E, Lord SR, Meyerkort P, McCloskey I, Fitzpatrick R: Blood pressure changes on upright tilting predict falls in older people. Age Ageing 2002, 31:181-186.

27. Maurer MS, Cohen $\mathrm{S}, \mathrm{Cheng} \mathrm{H}$ : The degree and timing of orthostatic blood pressure changes in relation to falls in nursing home residents. J Am Med Dir Assoc 2004, 5:233-238.

28. Aronow WS, Fleg JL, Pepine CJ, Artinian NT, Bakris G, Brown AS, Ferdinand KC, Forciea MA, Frishman WH, Jaigobin C, Kostis JB, Mancia G, Oparil S, Ortiz E, Reisin E, Rich MW, Schocken DD, Weber MA, Wesley DJ, Harrington RA, Bates ER, Bhatt DL, Bridges CR, Eisenberg MJ, Ferrari VA, Fisher JD, Gardner TJ, Gentile F, Gilson MF, Hlatky MA: ACCF/AHA 2011 expert consesus document on hypertension in the elderly: a report of the American College of Cardiology Foundation Task Force on Clinical Expert Consensus Documents. J Am Coll Cardiol 2011, 57:2037-2114. 
29. Sabayan B, Oleksik AM, Maier AB, Van Buchem MA, Poortvliet RKE, De Ruijter W, Gussekloo J, De Craen AJM, Westendorp RGJ: High blood pressure and resilience to physical and cognitive decline in the oldest old: The Leiden 85-Plus Study. JAGS 2012, 60:2014-2019.

30. Rapp K, Becker C, Cameron ID, Klenk J, Kleiner A, Bleibler F, König H,

Büchele G: Femoral fracture rates in people with and without disability. Age Ageing 2012, 41:653-658.

doi:10.1186/1471-2318-13-50

Cite this article as: Klein et al: Blood pressure and falls in communitydwelling people aged 60 years and older in the VHM\&PP cohort. BMC Geriatrics 2013 13:50.

\section{Submit your next manuscript to BioMed Central and take full advantage of:}

- Convenient online submission

- Thorough peer review

- No space constraints or color figure charges

- Immediate publication on acceptance

- Inclusion in PubMed, CAS, Scopus and Google Scholar

- Research which is freely available for redistribution 